\title{
Editorial
}

\section{Reviewers for 2015}

The Ghana Medical Journal continues to be grateful for the contribution of individuals who support its peerreview mechanism. Reviewers of manuscripts for journals work quietly but effectively to maintain the standards and the quality of the manuscripts that finally get published. Their contribution requires recognition. The professional regulatory body for medicine and dentistry practice in Ghana recognizes peer-review for as a continuing professional activity for the award of credits towards re-certification. Many of the reviewers who fell in the 2015 time period were recommended to the regulatory body for the award of CME credits. We will pursue this arrangement and look for other ways of rewarding all of our reviewers. The Ghana Medical Journal is grateful for the voluntary service provided by the following reviewers for the year 2015 .

Reviewer
Abdulai, Alhassan
Ackuaku-Dogbe, Edith
Adanu, Richard
Adei, Eunice
Adeyemi, Adewale
Adjei, George
Adu, Dwomoa
Adusi-Poku, Yaw
Ajayi, Isaac
Akpalu, Josephine
Anim, J Tei
Aniteye, Ernest
Ansong, Daniel
Appiah-Opong, Regina
Archampong, Timothy
Asare, J. B
Asuquo, Marcus
Baddoo, Henry
Baidoo, Kenneth
Biritwum, Richard
Boima, Vincent
Braimah, Ramat
Bruce, Ishmael
Darko, Rudolph
Dey, Ida
Dodoo, Alexander
Dodor, Emmanuel
Doku, Victor
Donkor, Peter
Edwin, Frank
Ekem, Ivy

Ghana

Ghana

United Kingdom

Ghana

Ghana

Ghana

\section{Reviewer}

Fasunla, Ayotunde

Ganyaglo, Gabriel

Issah, Kofi

Johnson, Ofonime

Kitcher, Emmanuel

Kwamin, Francis

Labi, Appiah-Korang

Lartey, Margaret

Malm, Keziah

Mensah, Samuel

Newman, Mercy

Nkrumah, Francis

Nnadi, Mathias

Obiri-Yeboah, Solomon

Oboirien, Muhammad

Ocran, Joseph

Odoi-Agyarko, Kwesi

Ofori-Adjei, David

Ofori-Adjei, Yaw

Ofosu, Anthony

Ohene-Yeboah, Michael

Ohene, Sally-Ann

Olatunji, Ayodeji

Ologe, Foluwasayo

Onotai, Lucky

Opintan, Japheth

Oreagba, Ibrahim

Oreagba, Ibrahim

Osafo, Yaw

Owusu, Isaac

Sabblah, George

Sackey, Adziri

Seffah, Joseph

Shunmugavelu, Karthik

Tachi, Kenneth

Turkson, Paa Kobina

Vanotoo, Linda

Wilson, Michael

Wiredu, Edwin

Yawson, Alfred

Yorke, Ernest

Yunus, Md
Country

Nigeria

Ghana

Ghana

Nigeria

Ghana

Ghana

Ghana

Ghana

Ghana

Ghana

Ghana

Ghana

Nigeria

Ghana

Nigeria

Ghana

Ghana

Ghana

Ghana

Ghana

Ghana

Ghana

Nigeria

Nigeria

Nigeria

Ghana

Nigeria

Nigeria

Ghana

Ghana

Ghana

Ghana

Ghana

India

Ghana

Ghana

Ghana

Ghana

Ghana

Ghana

Ghana

India

\section{Change in page layout}

The Editorial Committee has approved a change in the lay out of the pages of the journal. The changes include the use of full names of authors, format of the summary and the header and footer of each page. 